\title{
Evidence of advanced stage colorectal cancer with longer diagnostic intervals: a pooled analysis of seven primary care cohorts comprising 11720 patients in five countries
}

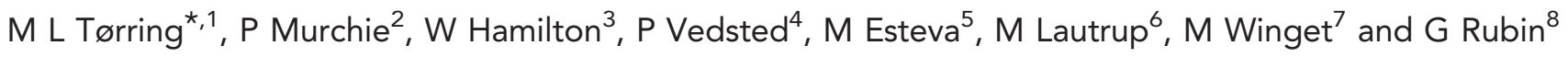

${ }^{1}$ Department of Anthropology, School of Culture and Society, Aarhus University, Moesgaard Allé 20, Højbjerg DK-8270, Denmark; ${ }^{2}$ Division of Applied Health Sciences, Centre of Academic Primary Care, University of Aberdeen, Polwarth Building, Foresterhill, Aberdeen AB25 2ZD, UK; ${ }^{3}$ University of Exeter, College House, St Luke's Campus, Magdalen Road, Exeter EX1 2 LU, UK; ${ }^{4}$ Research Unit for General Practice, Research Centre for Cancer Diagnosis in Primary Care, Aarhus University, Bartholins Allé 20, Aarhus C DK-8000, Denmark; ${ }^{5}$ Primary Care Research Unit, Primary Care Majorca Department, Balearic Islands Health Research Institute (IdISBa), Reina Esclaramunda 9, Palma Mallorca 07003, Spain; ' Department of Organ and Plastic Surgery, Breast Centre, Vejle Hospital, Kabbeltoft 25, Vejle DK-7100, Denmark; ${ }^{7}$ Division of Primary Care and Population Health, Department of Medicine, Stanford University School of Medicine, 1265 Welch Road, MSOB \#X214, Stanford, California CA 94305, USA and ${ }^{8}$ School of Medicine, Pharmacy and Health, Wolfson Research Institute, Durham University, Queen's Campus, University Boulevard, Stockton on Tees, England TS17 6BH, UK
\end{abstract}

Background: The benefits from expedited diagnosis of symptomatic cancer are uncertain. We aimed to analyse the relationship between stage of colorectal cancer (CRC) and the primary and specialist care components of the diagnostic interval.

Methods: We identified seven independent data sets from population-based studies in Scotland, England, Canada, Denmark and Spain during 1997-2010 with a total of 11720 newly diagnosed CRC patients, who had initially presented with symptoms to a primary care physician. Data were extracted from patient records, registries, audits and questionnaires, respectively. Data sets were required to hold information on dates in the diagnostic interval (defined as the time from the first presentation of symptoms in primary care until the date of diagnosis), symptoms at first presentation in primary care, route of referral, gender, age and histologically confirmed stage. We carried out reanalysis of all individual data sets and, using the same method, analysed a pooled individual patient data set.

Results: The association between intervals and stage was similar in the individual and combined data set. There was a statistically significant convex ( $\cap$-shaped) association between primary care interval and diagnosis of advanced (i.e., distant or regional) rather than localised CRC $(P=0.004)$, with odds beginning to increase from the first day on and peaking at 90 days. For specialist care, we saw an opposite and statistically significant concave ( $\cup$-shaped) association, with a trough at 60 days, between the interval and diagnosis of advanced CRC $(P<0.001)$.

Conclusions: This study provides evidence that longer diagnostic intervals are associated with more advanced CRC. Furthermore, the study cannot define a specific 'safe' waiting time as the length of the primary care interval appears to have negative impact from day one.

*Correspondence: ML Tørring; E-mail: mlt@cas.au.dk

Received 15 February 2017; revised 24 May 2017; accepted 29 June 2017; published online 8 August 2017

(C) 2017 Cancer Research UK. All rights reserved 0007-0920/17 
The diagnostic interval for cancer is defined as the time from first presentation of symptoms in primary care to diagnosis (Weller et al, 2012). There is a general public perception - largely shared by health professionals - that prolonged diagnostic intervals lead to poorer cancer outcome (Richards, 2009). Existing epidemiological evidence on the relationship between diagnostic interval and outcomes in colorectal cancer (CRC) is contradictory, most of it suggesting no statistically significant association (Ramos et al, 2007, 2008; Neal et al, 2015). Many of these studies are undermined by negative bias due to confounding by indication and lead-time, but the lack of clear evidence has nonetheless led some to question the current use of healthcare and research resources to reduce cancer delays (Rupassara et al, 2006; Murchie et al, 2014).

Most CRC patients present initially to a primary care physician (PCP) and are subsequently referred to specialist cancer centres for assessment and investigation (Hamilton and Sharp, 2004; Hamilton, 2010; Hansen et al, 2011; Banks et al, 2014). National guidelines such as the English NICE Guidance, the Scottish SIGN Guidelines and the Danish Cancer Patient Pathways, recommend urgent referral of patients with alarm signs and symptoms, including unexplained weight loss, change in bowel habit and/or rectal bleeding (NICE, 2005; SIGN, 2003; Probst et al, 2012). However, over half of people subsequently diagnosed with colorectal cancer have no alarm signs or symptoms at initial presentation to a PCP (Hamilton et al, 2005). These patients may experience longer diagnostic intervals, perhaps as a result of not being referred until alarm symptoms develop, or because they are ineligible for an urgent appointment (Neal et al, 2014; Jensen et al, 2014a).

We propose a temporal and relational way of understanding the association between time to diagnosis and CRC outcomes. In short, the temporal idea is that cancers become gradually easier to detect with time due to the exponential growth of tumours. The relational idea is that doctors exert their ability to identify cancer by virtue of the role they perform within the relational network to which they belong. It is our hypothesis that symptomatic cancer patients are being sorted and diagnosed at different pace based on their gradually changing clinical indications, and on the respective diagnostic tools available in primary and specialist care. This must be taken into account when analysing the prognostic influence of delays.

We identified seven CRC cohort studies to create a data set sufficiently large to investigate the association between time to diagnosis and CRC outcomes. To call attention to the inevitable problem of confounding by indication and explain continued lack of evidence, we analysed stage of CRC as a flexible function of the length of time under PCP care and specialist care, respectively.

\section{MATERIALS AND METHODS}

We identified seven studies with data sets from Scotland, England, Canada, Denmark and Spain from population-based studies of incident CRC patients diagnosed between 1997 and 2010. Data sets were required to hold information on dates in the diagnostic interval (Weller et al, 2012), symptoms at first presentation in primary care, route of referral, gender, age and stage. All but one (ALBERTA) have published their results (Robertson et al, 2004; Hamilton et al, 2005; Stapley et al, 2006; Korsgaard et al, 2006a, b; Esteva et al, 2007, 2013; Rubin et al, 2011; Lyratzopoulos et al, 2013; Murchie et al, 2014; Jensen et al, 2014b). The individual studies are summarised in Table 1 and more extensively described in the Supplementary Material I.

Study population. All cohorts described in this study were from jurisdictions with publicly funded, universal health-care systems, in which PCPs act as gatekeepers from primary to specialist care.
Newly diagnosed CRC patients were identified in discharge registries, hospital or primary care records. From each data set, we included all patients aged 20 years and over who had attended primary care before the cancer diagnosis. Screen-detected cases were excluded, as were those diagnosed as a result of emergency presentation with no prior contact with primary care. To render the data sets uniform, we only included patients with recorded CRC symptoms or CRC-related visits in the year before diagnosis (Stapley et al, 2006).

Defining exposures, outcome and covariates. We defined and calculated three exposure variables as illustrated on Figure 1: (1) The primary care interval (time from first presentation to referral to a cancer specialist centre); (2) the secondary care interval (time from referral to diagnosis); and (3) the total diagnostic interval (time from first presentation to diagnosis) based on information on date of first presentation of symptoms in primary care and date of referral to a cancer specialist centre, and date of diagnosis, as defined in the Aarhus Statement (Weller et al, 2012). All data sets, except the NACDPC, recorded the date of diagnosis, defined as date of first histological confirmation of the malignancy in accordance with the hierarchy produced by the European Network of Cancer Registries (Supplementary Material I).

The primary outcome of the study was stage of CRC as defined by the local registry or provincial cancer registry in the case of the ALBERTA cohort (Table 1). All data sets included histologically confirmed stage, except the NACDPC data set, which used a simplified staging equating to SEER stages $0-3$ that was determined by the PCP using information contained in cancer specialist letters. We used T, N and M and not Dukes' stage where both were available. Stage data were re-categorised to localised, regional, distant, or unknown; and then further simplified to a binary variable of advanced (i.e., distant or regional) vs localised CRC (Supplementary Table 1 shows the algorithm for colorectal cancer staging according to classification system).

All data sets included data on gender, age at diagnosis and presenting symptoms. 'Alarm symptoms at first presentation' (yes/ no), were defined based on whether patients' reported symptom(s) merited urgent referral according to the UK's NICE guidelines (NICE, 2005; Neal et al, 2014) (Supplementary Table 2 shows the pre-specified lists of colorectal cancer symptoms recorded in each data set).

Statistical analyses. Each data set was analysed separately, then combined for pooled individual patient data analysis. Time intervals are presented as medians with interquartile intervals (IQI). To test for confounding factors related to clinical triage, we estimated the difference in median care intervals between patients with and without 'alarm symptoms' and 'emergency admission' or not using quantile regression analysis (Supplementary Table 3; Supplementary Figures 4 and 5).

To avoid assuming a linear or piecewise constant association between care intervals and stage, we treated primary and secondary care intervals as continuous variables, using restricted cubic splines with three knots and 30 days as the reference point (Durrleman and Simon, 1989). We estimated the odds ratio of being diagnosed with advanced $v s$ localised CRC as a function of the length of each care interval using logistic regression. We adjusted for age (20-64/ $65-74 / \geqslant 75$ years), gender and alarm symptoms. With the combined data, we allowed for between-data set variability by adjusting for cohort. We combined interval data with no attention to distributions or weights. Eight sensitivity analyses tested the robustness of the model (Supplementary Table 5).

We tested each model against a model with no care interval term using the Wald test. A two-sided $P$-value of 0.05 or less was defined as significant. Analyses were done using Stata v. 14 (StataCorp LP, College Station, TX, USA). 
Table 1. Study characteristics of seven colorectal cancer cohort data sets

\begin{tabular}{|c|c|c|c|c|c|c|c|}
\hline $\begin{array}{l}\text { Cohort } \\
\text { name }\end{array}$ & CRUX & CAPER & CRCDK & ALBERTA & CAP & DECCIRE & NACDPC \\
\hline Project & $\begin{array}{c}\text { Comparing rural and urban } \\
\text { cancer care }\end{array}$ & $\begin{array}{l}\text { Cancer prediction in } \\
\text { Exeter }\end{array}$ & $\begin{array}{c}\text { Colorectal cancer in } \\
\text { Denmark }\end{array}$ & Not named & Cancer in primary care & Delay cancer colon i recto & $\begin{array}{l}\text { National audit of cancer } \\
\text { diagnosis in primary care }\end{array}$ \\
\hline Reference & $\begin{array}{l}\text { Robertson et al, 2004; } \\
\text { Murchie et al, } 2014\end{array}$ & $\begin{array}{l}\text { Hamilton et al, 2005; } \\
\text { Stapley et al, } 2006\end{array}$ & $\begin{array}{l}\text { Korsgaard et al, 2006a, } \\
\text { 2006b; Iversen et al, } 2009\end{array}$ & Unpublished & $\begin{array}{c}\text { Jensen et } a l, 2014 a \\
2014 b\end{array}$ & Esteva et al, 2007, 2013 & $\begin{array}{l}\text { Rubin et al, 2011; } \\
\text { Lyratzopoulos et al, } 2013\end{array}$ \\
\hline Population & Scotland & England & Denmark & Canada & Denmark & Spain & England \\
\hline Region/county & $\begin{array}{l}\text { Highland and Grampian } \\
\text { regions }\end{array}$ & Devon county & $\begin{array}{l}\text { Aarhus, Ringkoebing and } \\
\text { Ribe counties }\end{array}$ & Province of Alberta & $\begin{array}{c}\text { Aarhus County (CAP1) } \\
\text { Central and Southern DK } \\
\text { (CAP2) } \\
\text { All of Denmark (CAP3) }\end{array}$ & $\begin{array}{l}\text { Baleares, Galicia, } \\
\text { Valencia, Catalunya and } \\
\text { Aragón regions }\end{array}$ & $\begin{array}{l}1170 \text { volunteering practices } \\
\text { from } 20 \text { Cancer Networks } \\
\text { representing } 14 \% \text { of all } \\
\text { practices in England }\end{array}$ \\
\hline Study period & Jan 1997-Dec 1998 & Jan 1998-Dec 2002 & Jan 2001-July 2002 & Jan 2004-Dec 2008 & $\begin{array}{c}\text { Sept 2004-Aug } 2005 \\
\text { (CAP1) } \\
\text { Oct 2007-Sept } 2008 \\
\text { (CAP2) } \\
\text { May 2010-Aug 2010 } \\
\text { (CAP3) }\end{array}$ & Sept 2006-Sept 2008 & April 2009-April 2010 \\
\hline Study design & Registry-based & Registry-based & Patient-based & Registry-based & PCP-based & Patient-based & PCP-based \\
\hline Identification & Scottish Cancer Registry & Exeter Cancer Registry & Hospital departments & Provincial Cancer Registry & $\begin{array}{l}\text { Hospital Discharge } \\
\text { Registry }\end{array}$ & Hospital departments & English Cancer Networks \\
\hline $\begin{array}{l}\text { Disease } \\
\text { classification }\end{array}$ & ICD-10 C18, C19 and C20 & $\begin{array}{c}\text { ICD-O-3 8140, 8480, 8490, } \\
8020\end{array}$ & $\mathrm{ICD}-10 \mathrm{C} 18, \mathrm{C} 19$ and $\mathrm{C} 20$ & ICD-10 C18, C19 and C20 & ICD-10 C18, C19 and C20 & ICD-9 153-154 & ICD-10 C18, C19 and C20 \\
\hline Validation & Histological confirmation & Histological confirmation & $\begin{array}{l}\text { Histological confirmation } \\
\text { (Pathology reports) }\end{array}$ & Histological confirmation & $\begin{array}{r}\text { Histological confirmation } \\
\text { (Danish Cancer Registry) }\end{array}$ & $\begin{array}{c}\text { Histological confirmation } \\
\text { (pathology reports) }\end{array}$ & $\begin{array}{l}\text { Practice records including } \\
\text { hospital correspondence }\end{array}$ \\
\hline Data sources & $\begin{array}{l}\text { Primary care records and } \\
\text { governmental hospital } \\
\text { admissions data }\end{array}$ & $\begin{array}{l}\text { Electronic primary care } \\
\text { record }\end{array}$ & $\begin{array}{l}\text { Interviewer-administered } \\
\text { patient questionnaires }\end{array}$ & $\begin{array}{l}\text { Physician billings and } \\
\text { hospital records }\end{array}$ & $\begin{array}{c}\text { PCP-questionnaires } \\
\text { requesting dates from } \\
\text { electronic patient files } \\
\text { and hospital discharge } \\
\text { letters }\end{array}$ & $\begin{array}{c}\text { Patient interviews } \\
\text { combined with review of } \\
\text { primary care and hospital } \\
\text { records }\end{array}$ & $\begin{array}{l}\text { PCP-audit tool requesting } \\
\text { dates from practice records } \\
\text { and hospital correspondence }\end{array}$ \\
\hline Definitions & Algorithm & Case-Control review & Interview & Algorithm & Questionnaire & Interview and review & Audit \\
\hline $\begin{array}{l}\text { Date of } \\
\text { presentation }\end{array}$ & $\begin{array}{c}\text { Earliest recorded } \\
\text { colorectal cancer symptom } \\
\text { in the year before } \\
\text { diagnosis }\end{array}$ & $\begin{array}{c}\text { Earliest recorded } \\
\text { colorectal cancer symptom } \\
\text { in the year before date of } \\
\text { diagnosis }\end{array}$ & $\begin{array}{c}\text { 'When did you first present } \\
\text { the above stated } \\
\text { symptoms to a doctor?' }\end{array}$ & $\begin{array}{c}\text { The earlier of: first } \\
\text { recorded CRC symptom } \\
\text { or PCP visit prior to first } \\
\text { CRC procedure in the year } \\
\text { before diagnosis }\end{array}$ & $\begin{array}{l}\text { 'When did the patient first } \\
\text { present to your practice } \\
\text { with symptoms which you } \\
\text { think are related to the } \\
\text { current cancer diagnosis?' }\end{array}$ & $\begin{array}{l}\text { Researchers browsed } \\
\text { primary care records }\end{array}$ & $\begin{array}{c}\text { First notification to any } \\
\text { health-care professional } \\
\text { working within the Primary } \\
\text { Health-Care Team about a } \\
\text { probable symptom or sign of } \\
\text { cancer }\end{array}$ \\
\hline Date of referral & $\begin{array}{l}\text { Date of first PCP referral or } \\
\text { date of emergency } \\
\text { admission to hospital }\end{array}$ & Not collected & $\begin{array}{l}\text { 'When were you referred } \\
\text { to hospital for further } \\
\text { investigation?' }\end{array}$ & $\begin{array}{l}\text { Date of first PCP visit prior } \\
\text { to colonoscopy or other } \\
\text { CRC-related procedure }\end{array}$ & $\begin{array}{l}\text { 'At which date did you/ } \\
\text { your practice decide to } \\
\text { refer the patient for } \\
\text { further investigation?' }\end{array}$ & $\begin{array}{c}\text { Researchers browsed } \\
\text { primary care records, but } \\
\text { not in the Aragón region } \\
(n=214)\end{array}$ & $\begin{array}{l}\text { Referral to secondary care for } \\
\text { further investigation or } \\
\text { management of probable } \\
\text { symptom or sign of cancer }\end{array}$ \\
\hline Date of diagnosis & $\begin{array}{l}\text { Scottish Cancer Registry } \\
\text { incidence date }\end{array}$ & $\begin{array}{c}\text { Date of positive histology } \\
\text { or date given by the } \\
\text { specialist }\end{array}$ & $\begin{array}{l}\text { 'What decisive } \\
\text { examination led to your } \\
\text { current hospitalisation?' }\end{array}$ & $\begin{array}{c}\text { Date in cancer registry } \\
\text { which is almost always the } \\
\text { date of first positive } \\
\text { histology }\end{array}$ & $\begin{array}{l}\text { Danish Cancer Registry } \\
\text { incidence date }\end{array}$ & $\begin{array}{l}\text { Date of positive histology } \\
\text { (date of the first } \\
\text { pathology report) }\end{array}$ & Not collected \\
\hline Tumour stage & Dukes & Dukes & Dukes and TNM & TNM & TNM & TNM & SEER 2-4 \\
\hline Symptom data & 17 CRC symptoms (ICPC) & 11 CRC symptoms (ICPC) & $\begin{array}{c}17 \text { CRC symptoms } \\
\text { (patients' first symptom } \\
\text { experience) }\end{array}$ & 12 CRC symptoms & $\begin{array}{l}11-22 \text { cancer symptoms } \\
\text { presented in primary care }\end{array}$ & $\begin{array}{c}9 \mathrm{CRC} \text { symptoms } \\
\text { (patients' first symptom } \\
\text { experience) }\end{array}$ & 11 CRC symptoms (ICPC) \\
\hline $\begin{array}{l}\text { Emergency } \\
\text { admission }\end{array}$ & $\begin{array}{l}\text { Type of first hospital } \\
\text { visit=A\&E and emergency } \\
\text { admission according to } \\
\text { hospital admission data }\end{array}$ & $\begin{array}{l}\text { Surgical admission for } \\
\text { suspected bowel } \\
\text { obstruction or perforation } \\
\text { with CRC diagnosed } \\
\text { during admission }\end{array}$ & $\begin{array}{l}\text { 'How were you admitted to } \\
\text { the surgical department' } \\
\text { response: acute or sub- } \\
\text { acute admission }\end{array}$ & $\begin{array}{c}\text { Emergency admission with } \\
\text { CRC-related issue within } 7 \\
\text { days prior to diagnosis }\end{array}$ & $\begin{array}{l}\text { Acute or sub-acute } \\
\text { admission according to } \\
\text { National Patient Registry } \\
\text { NB: Not collected for the } \\
\text { second and third } \\
\text { subcohort ( } n=1569 \text { ) }\end{array}$ & $\begin{array}{c}\text { Route to } \\
\text { diagnosis = emergency } \\
\text { department according to } \\
\text { hospital record }\end{array}$ & $\begin{array}{l}\text { Type of referral=emergency } \\
\text { according to primary care } \\
\text { record (audit tool) }\end{array}$ \\
\hline
\end{tabular}

Abbreviations: CRC = colorectal cancer; ICD-10 = International Classification of Diseases 10th revision; ICD-9 International Classification of Diseases 9th revision; ICD-O-3 = WHO International Classification of Disease for Oncology; ICPC = International Classification of Primary Care; PCP = primary care physician; SEER = Surveillance, Epidemiology and End Results (cancer reporting standard of the National Cancer Institute); TNM = Tumour, node, metastasis. Study characteristics of seven colorectal cancer cohort data set.

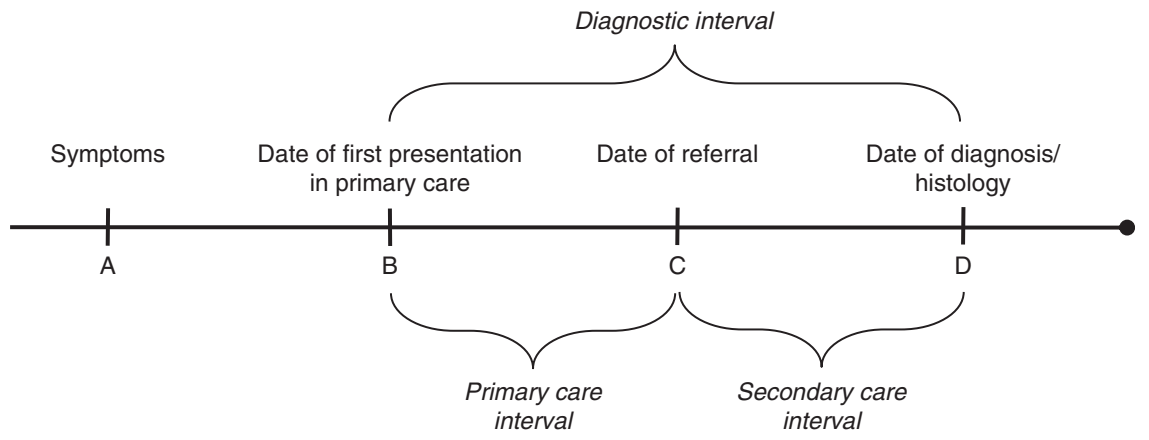

Figure 1. Definition of exposure variables. We calculated three exposure variables based on information on date of first presentation of symptoms in primary care (B); date of referral to a cancer specialist centre (C); and date of diagnosis (D). 'The primary care interval' is defined as (B, C) = time from first presentation to referral to a cancer specialist centre. 'The secondary care interval' is defined as $(\mathbf{C}, \mathbf{D})=$ time from referral to diagnosis). 'The total diagnostic interval' is defined as $(\mathbf{B}, \mathbf{D})=$ time from first presentation to diagnosis. Information on date of first symptom $(\mathbf{A})$ was not available. 


\section{RESULTS}

In total, the seven data sets included 15023 incident CRC patients. Of these, 1584 (11\%) did not consult a PCP before their diagnosis of CRC, and 1719 had incomplete data; these were excluded. Of the remaining 11720 patients, 11187 (95\%) had information on primary care interval; $9163(78 \%)$ on secondary care interval and $9696(83 \%)$ on the total diagnostic interval. Stage information was available for $92 \%$ (Table 1 and Figure 2).

The median age for all patients combined was 70 years; $56 \%$ were males, 59\% presented with alarm symptoms, $20 \%$ were emergency hospital admissions, $61 \%$ had colon and $39 \%$ rectal cancer; $44 \%$ had localised CRC. Clinical features were remarkably similar for each of the seven cohorts, except for the proportion of patients presenting with alarm symptoms, which varied from $49 \%$ (DECIRRE) to $78 \%$ (CAPER); and the proportion of emergency admissions, which varied from $10 \%$ (CRCDK) to $43 \%$ (DECCIRE) (Table 2).

Total diagnostic interval and its primary care and secondary care components. The overall median primary care interval was 5 days (interquartile interval (IQI): 0-39), ranging from 2 days (IQI: 0-21) in CAP to 14 days (IQI: 0-64) in CRUX. Thirty nine per cent of patients were referred immediately after presentation (i.e., primary care interval of zero days) varying from $14 \%$ in CRUX to $46 \%$ in the CAP and ALBERTA cohorts (Supplementary Figure 1). The overall median secondary care interval was 20 days (IQI: 7-46) and varied from 14 days (IQI: 7-29) in CRCDK to 38 days (IQI: 17-82) in DECCIRE (Table 2; Supplementary Figure 2). The overall median diagnostic interval was 46 days (IQI: 18-105) ranging from 35 days in CAP to 97 days in CAPER (Table 2; Supplementary Figure 3).

The adjusted care intervals were significantly shorter for patients with alarm symptoms and for patients with emergency admissions. Overall, patients waited an additional 6 (95\% confidence interval (CI): 4-7) days from presentation to referral and an additional 9 (95\% CI: 7-10) days from referral to diagnosis at the 50th percentile if they had no alarm symptoms. An emergency admission shortened the secondary care interval by 18 (95\% CI: 17-19) days at the 50th percentile. Alarm symptoms consistently shortened the length of the primary care interval in each cohort, whereas emergency admissions more convincingly affected the length of the secondary care interval (Supplementary Table 3; Supplementary Figures 4 and 5).

Primary and secondary care diagnostic intervals and stage of CRC. For the combined cohort, we observed a significant trend for a concave, $\cap$-shaped association with increasing and subsequently decreasing odds of advanced CRC with longer primary care intervals $(P=0.004)$. The point-wise estimates showed that the adjusted odds of being diagnosed with an advanced stage tumour increased from the first day, and were around 8\% (95\% CI: 2-12\%) higher for patients who waited 90 days compared to 30 days from first presentation to referral (Figure 3, blue curve). For the secondary care interval, we saw the reverse effect: a significant $\cup$-shaped association with decreasing and subsequently increasing odds of advanced CRC with longer secondary care intervals $(P<0.001)$ (Figure 3, red curve). Crude estimates were similar to the adjusted curves on Figure 3 (not shown).

The cohort-specific associations were consistent with the overall trend (Figures 4 and 5), but the primary care interval model was only significant for CRUX $(P=0.03)$; and the secondary care interval model was only significant for ALBERTA $(P<0.001)$ and CAP $(P<0.001)$ data. For the total diagnostic interval, we found decreasing odds of advanced CRC with longer intervals $(\mathrm{P}<0.001)$, but not achieving significance in individual cohorts (Supplementary Figure 6).

The findings were similar after including patients with unknown tumour stage (915 patients) or restricting the analysis to patients with/without alarm symptoms or with/without emergency admission. Excluding the $41 \%$ of patients with zero days of primary care interval (zero-inflation) decreased the primary care interval trend. These sensitivity analyses are shown in Supplementary Table 5.

\section{DISCUSSION}

In this unique pooled individual patient data analysis of seven cohorts with 11720 incident CRC patients attending primary care with symptoms before diagnosis, the odds of advanced CRC increased with longer primary care intervals up to $\sim 90$ days, after

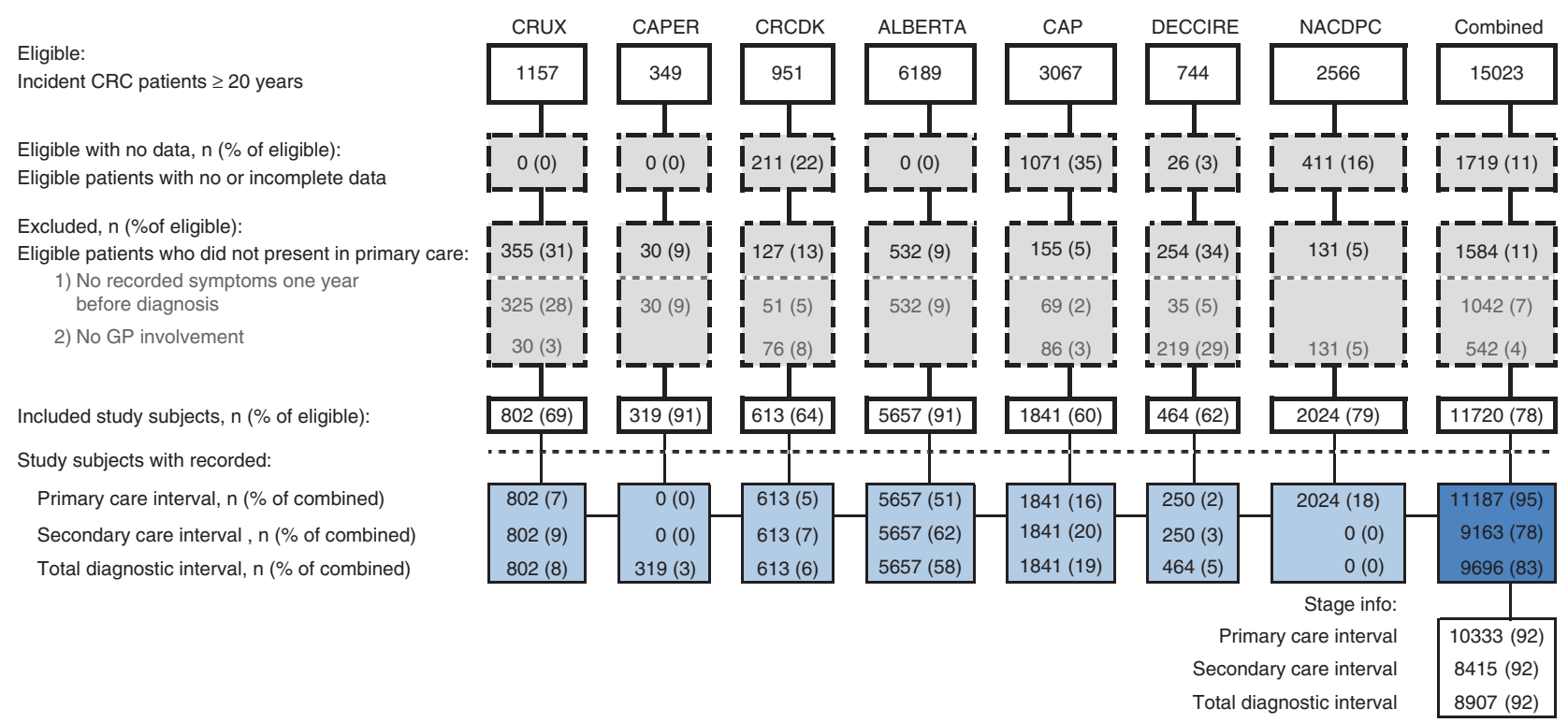

Figure 2. Patient flow for each colorectal cancer cohort data set and all data combined. CAP = Cancer in Primary Care; CAPER $=$ Cancer Prediction in Exeter; $\mathrm{CRC}=$ colorectal cancer; $\mathrm{CRCDK}=$ Colorectal Cancer in Denmark; CRUX = Comparing Rural and Urban Cancer Care; DECCIRE $=$ Delay Cancer Colon i Recto; NACDPD $=$ National Audit of Cancer Diagnosis in Primary Care. 
Table 2. Clinical features for patients attending general practice before diagnosis displayed for each colorectal cancer cohort data set and all data combined

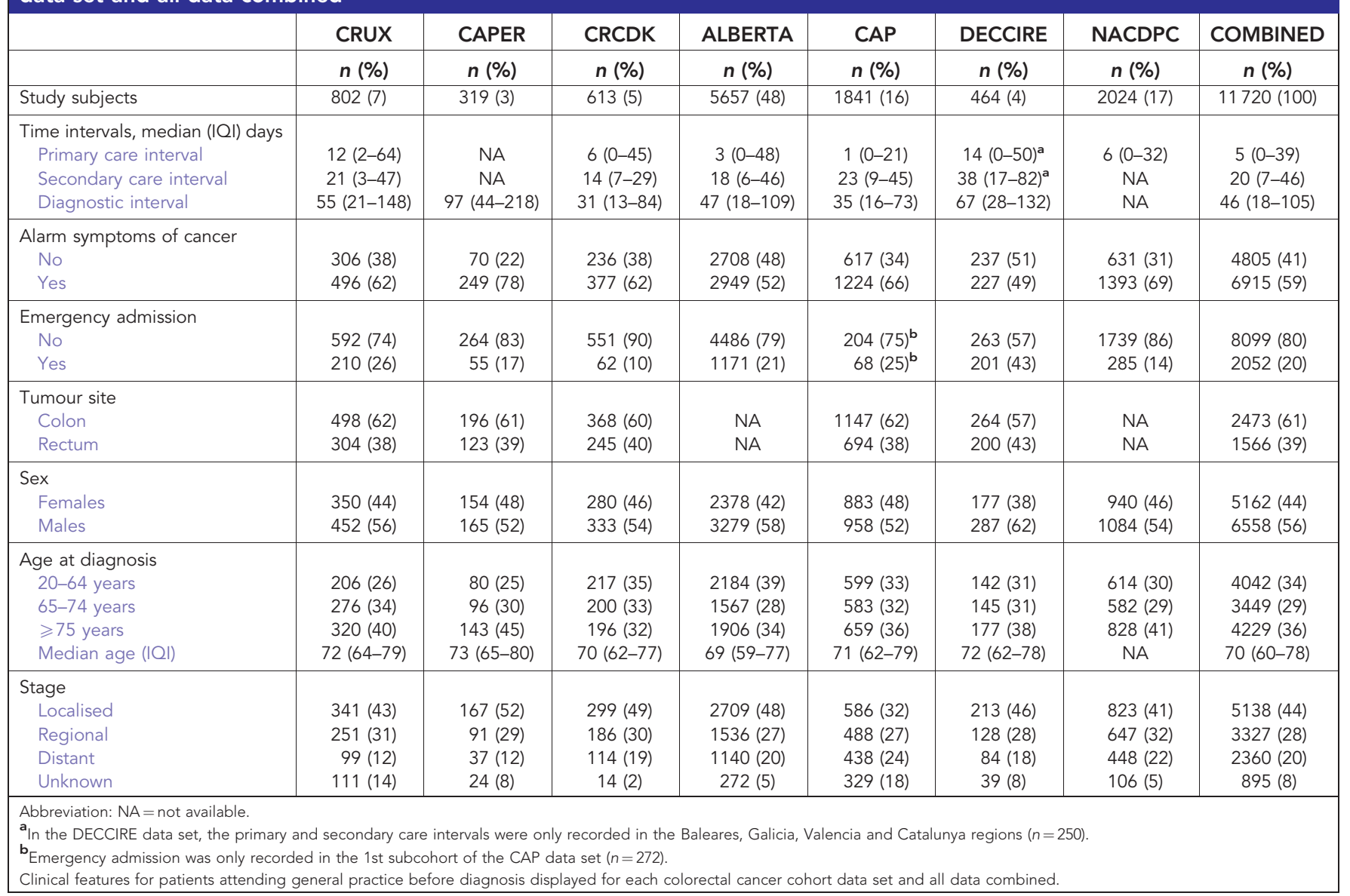

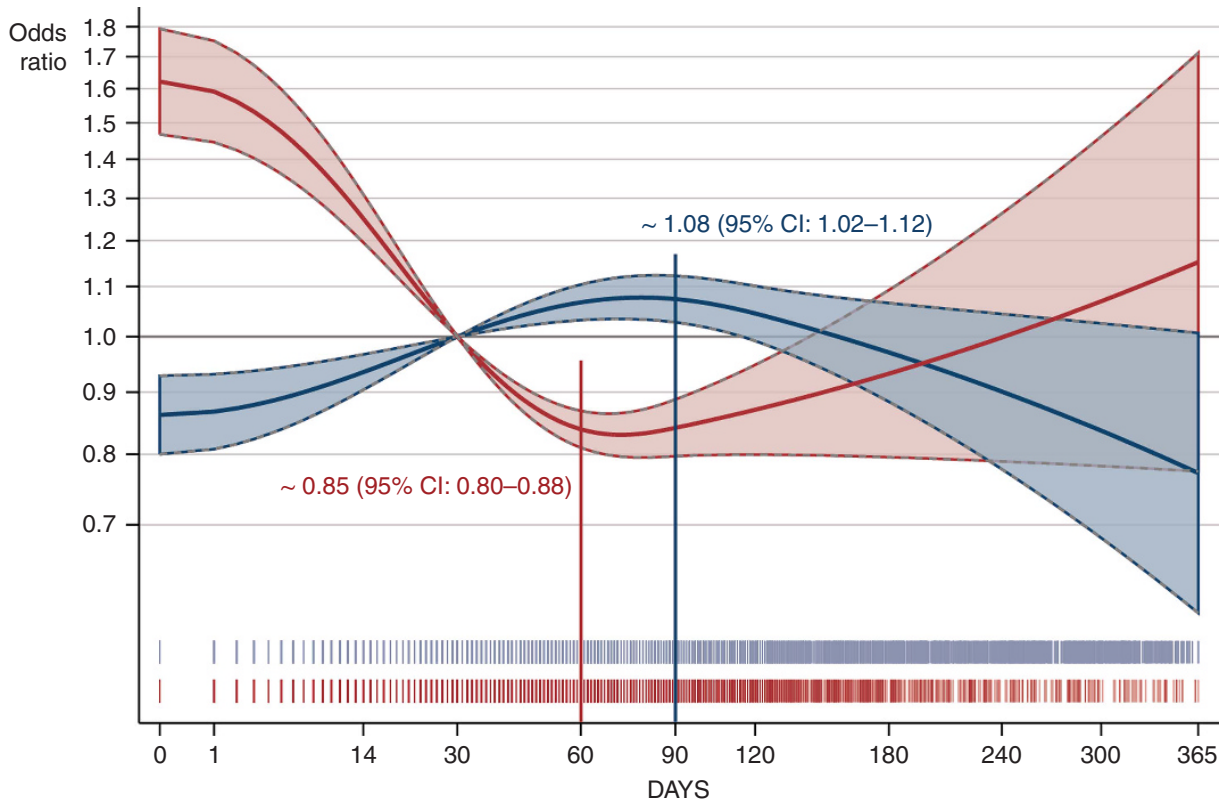

Blue: Primary care interval, combined $N=10333$

Red: Secondary care interval, combined $N=8415$

Figure 3. The risk of being diagnosed with advanced colorectal cancer as a function of time to diagnosis. Estimated odds ratios of being diagnosed with advanced (distant or regional) vs localised colorectal cancer as a function of the length of the primary care interval (blue) and the secondary care interval (red) analysed for all cohorts combined (patients with unknown tumour stage excluded). We adjusted for age, gender, alarm symptoms and cohort. The area around the fitted curves indicates $95 \%$ confidence limits. The spikes below the curves show the distribution of the primary care interval (blue) and secondary care interval (red) on a squared scale. The grey horizontal lines indicate the chosen reference point of 30 days (see logistic regression details in Supplementary Table'4, Supplementary Material IV). Crude estimates are not shown. 


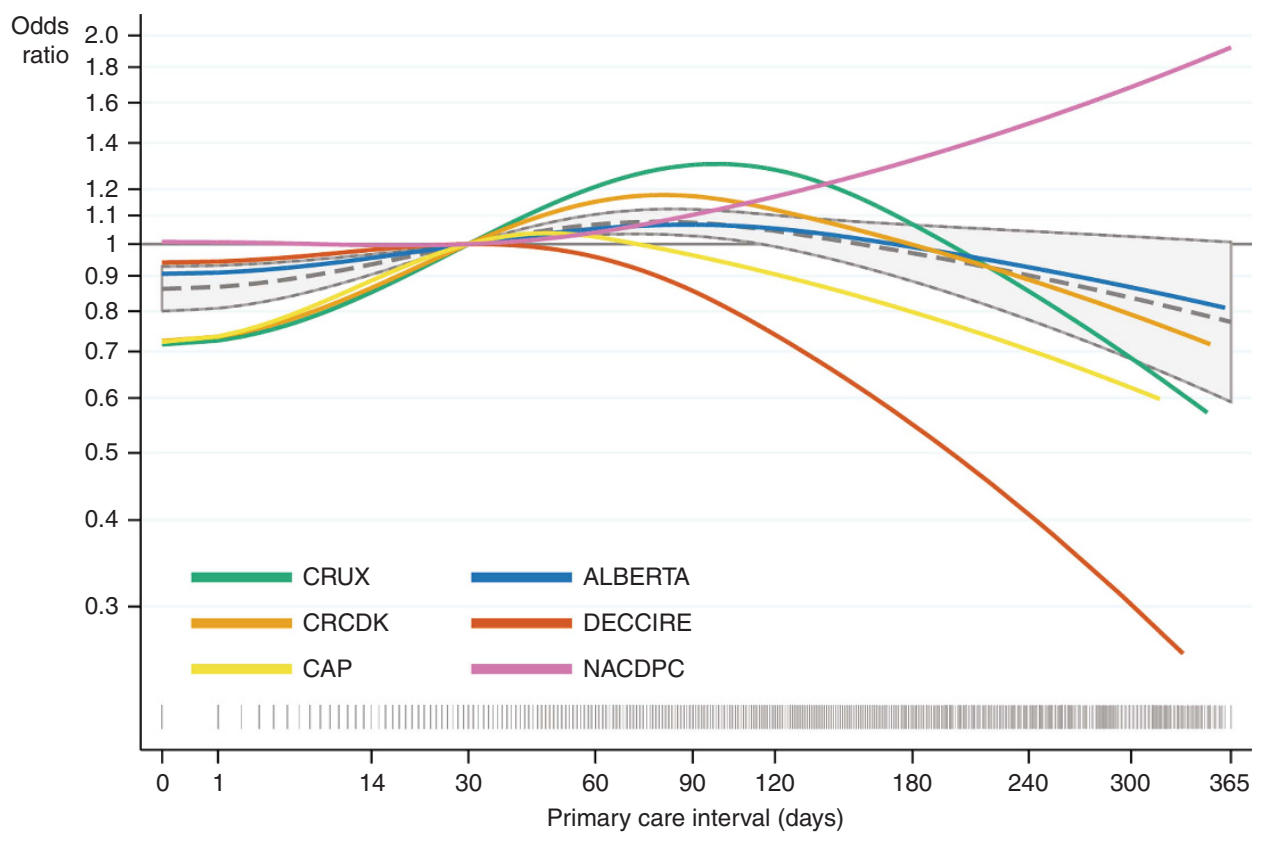

Figure 4. The risk of being diagnosed with advanced colorectal cancer as a function of time from presentation to referral. Estimated odds ratios of being diagnosed with advanced (distant or regional) vs localised colorectal cancer as a function of the length of the primary care interval (time from first presentation of symptoms to referral); analysed for six cohorts (in total 10333 patients). We excluded patients with unknown tumour stage excluded and adjusted for age, gender and alarm symptoms at first presentation. The grey dashed curves with $95 \%$ confidence limits are fitted on the combined data sets with grey spikes showing the distribution of the care intervals on a squared scale. The grey horizontal lines indicate the chosen reference point of 30 days. Crude estimates are not shown.

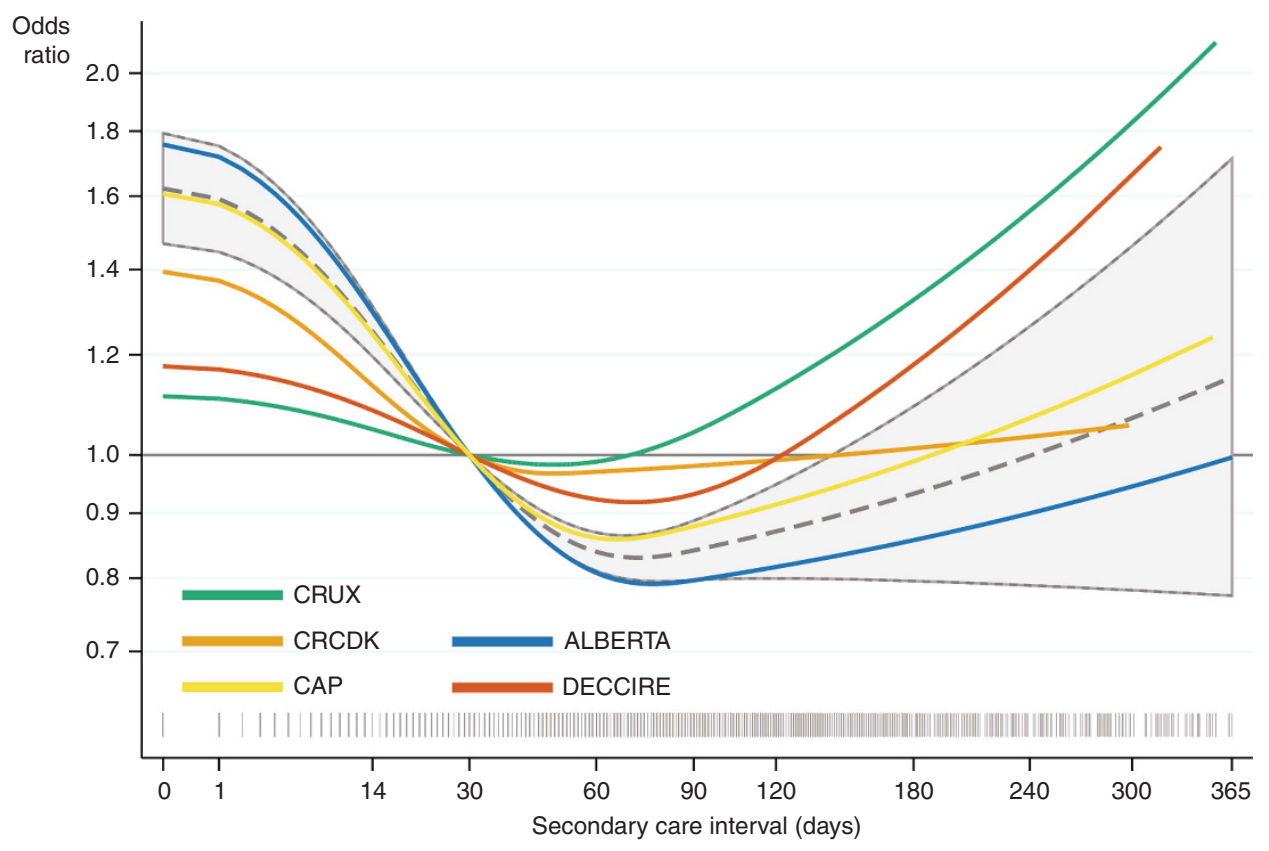

Figure 5. The risk of being diagnosed with advanced colorectal cancer as a function of time from referral to diagnosis. Estimated odds ratios of being diagnosed with advanced (distant or regional) vs localised colorectal cancer as a function of the length of the secondary care interval (time from referral to diagnosis) analysed for five cohorts (in total 8415 patients). We excluded patients with unknown tumour stage and adjusted for age, gender and alarm symptoms at first presentation. The grey dashed curves with $95 \%$ confidence limits are fitted on the combined data sets with grey spikes showing the distribution of the care intervals on a squared scale. The grey horizontal lines indicate the chosen reference point of 30 days. Crude estimates are not shown.

which the odds decreased. Conversely, the odds of advanced CRC decreased with longer secondary care intervals up to $\sim 60$ days, after which the odds slowly increased. Both of these associations were statistically significant and the trends were consistent across data sets. No clear trend was noted across individual cohorts for the total diagnostic intervals.
Strengths and limitations. The key strength of this study lies in the large number of cases, from seven data sets in five countries with comparable systems of universal health-care. By excluding screen-detected patients and those without PCP involvement, the results are relevant to all health-care systems featuring primary care gate-keeping. However, the proportions of patients presenting 
as an emergency are not routinely recorded outside the UK, so we cannot know whether varying sizes of this proportion have affected our results. The data were sufficiently detailed to enable care intervals to be analysed as a continuous variable, enabling us to utilise recent methodological advances in a larger sample (Tørring et al, 2011, 2012). A fundamental strength of the study is that leadtime bias cannot explain results, as we used stage as our outcome measure, rather than survival time.

A number of limitations exist due to the cross-sectional study design, which does not permit direct inference of causality. Dates for interval calculations may have been recorded systematically differently across different data sets. Although the ascertainment of dates accorded with best practice in all cases (Weller et al, 2012), no gold standard data source exists for interval measures. Studies show good agreement between patient and PCP recorded dates of diagnosis (Adelstein et al, 2008); but dates of first presentation are usually more accurately recorded for alarm symptoms than for non-specific symptoms (Lynch et al, 2008). Furthermore, registry-based interval measures may be affected by the data collection methods, with some symptoms unrecorded, whereas others are potentially unrelated to the cancer (Stapley et al, 2006; Tate et al, 2009). Registry-based studies are highly dependent on underlying algorithms and cut-points; they benefit from high inclusion rates, but potentially have non-differential misclassification of date of first presentation. To ensure that registry-based recorded symptoms were likely to be related to the cancer, we only included recorded CRC symptoms or CRC-related visits in the year before diagnosis. Even so, registry-based measures were longer than PCP-reported time points (Table 2; Supplementary Figures 1-3).

Missing information bedevils all studies on staging, and may have biased results if the quality of staging was associated with diagnostic timeliness. Although we used benchmarked registries and approaches to produce comparable stage information (Tucker et al, 1999; Ostenfeld et al, 2012; Walters et al, 2013; Benitez-Majano et al, 2016), it is conceivable that there was some bias to exclusion of more advanced cases in some data sets, reflecting those dying during admission or treatment. The main effect of such information bias would be increased variation and fewer cases with short intervals and advanced stages, and thus towards no association between time and stage. Hence, our estimates are perhaps underestimates of the real association.

Despite differences in data sources and construction, the clinical features of patients were remarkably similar for each of the seven individual data sets, and they produced strikingly similar results suggesting that selection and information biases were not major methodological limitations.

Unmeasured confounding by factors such as socioeconomic status, co-morbidity, or tumour grade/aggressiveness, which were not universally available, may have influenced the results. We partly mitigated this by adjusting for alarm symptoms and emergency admissions, reducing confounding by indication.

Given the observed trends, it is difficult to predict the direction of bias. However, most of the potential biases from selection, information, confounding, and confounding by indication inherited from the different study designs are likely to have caused negative bias towards and even beyond the null-hypothesis (i.e., odds ratio $=1$ ).

When interpreting the results from the combined data sets, the weight of information contributed by each study is relevant. In a sensitivity analysis excluding ALBERTA (50-61\% of subjects) we found almost identical results (Supplementary Table 5).

Comparison with findings from other studies. The study builds on a recent systematic review of the association between time to diagnosis and cancer outcome for all types of cancers, which called for higher quality and larger studies that addressed basic issues of bias (Neal et al, 2015). Few studies have considered the possibility that the associations may vary for different components of the diagnostic pathway (Afzelius et al, 1994; Crawford et al, 2002). They support our interpretation that the basis for assignment of delay (the sorting of patients) change during the diagnostic pathway and that interval-specific models are necessary to achieve valid comparisons of delay and mortality. Our findings also confirm a non-monotonic relationship between delay and stage, and thus consolidate important points made by Maguire and others, but in a much larger cohort enabling more valid models (Maguire et al, 1994; Tørring et al, 2011, 2012; Murchie et al, 2014).

Underlying mechanisms. It is a widely held assumption that the waiting time paradox can be explained by the effect of high-risk precursors such as phenotype, biological virulence or tumour aggressiveness, which are thought to act as unmeasured confounders that mask the effect of the exposure (Afzelius et al, 1994; Crawford et al, 2002; Symonds, 2002; Neal et al, 2015). However, some studies have shown that a significant proportion of cancers present with symptoms that are vague or non-specific, with the underlying problem more difficult to detect and act upon in time (Korsgaard et al, 2006b; Jensen et al, 2014a). It is reasonable to assume that symptomatic cancer patients are sorted and diagnosed at different pace based on their gradually changing clinical indications, and on the respective diagnostic tools available in primary and specialist care.

We believe the finding of a two-sided 'waiting time paradox' (lower odds of advanced CRC for very long primary care intervals and higher odds of advanced CRC for very short secondary care intervals) reflects confounding by indication, a bias stemming from the inherent difference in the prognosis of patients given different medical priority in primary care $v s$ specialist care.

In primary care, PCPs will expedite patients using a fast-track cancer patient pathway or emergency admission if the patient's illhealth is obvious. At the same time, PCPs may be more reluctant to refer those with low-risk symptoms, leading to use of normal waiting list referral or watchful-waiting. As many patients in primary care do not fall squarely into either of these categories, delays should be less contingent upon prognosis and thus more randomly distributed in the large group of intermediate patients. We, therefore, propose that the observed increasing odds of advanced CRC with longer primary care intervals up to $\sim 90$ days reflects the actual effect of primary care delays.

In contrast, when a patient is first seen in specialist care, primary care triage has already taken place-making the probability of CRC higher. Furthermore, the specialist's greater clinical experience of patients with CRC and ready access to hospital-based investigations ensures that patients with advanced disease attending specialist care are diagnosed and treated very quickly; those with less advanced disease are managed less urgently. Hence, negative bias (where the observed effect is lower than the true value) probably explains the decreasing odds of advanced CRC with time and may explain why many CRC studies to date have failed to reject the null-hypothesis of no association between delays and outcome (Ramos et al, 2007, 2008; Neal et al, 2015). As with previous studies, we found no clear association between the total diagnostic interval and stage, presumably due to the conflicting selection-effects of primary care and secondary care intervals. As a final, tentative point, we propose that the observation of increasing odds of advanced CRC with secondary care intervals longer than $\sim 60$ days could reflect the effect of false negative tests or unnecessary delays in investigation and/or treatment.

Clinical implications. We cannot define a specific 'safe' waiting time as the length of the primary care interval appears to have a 
negative impact from day one. It follows that patients with CRC, without alarm symptoms at presentation, are most at risk of a prolonged diagnostic interval.

Cancer diagnostic delays cannot be completely eradicated, so resources must be used proportionately to the objective of finding cancer sooner. Reducing the primary care interval by lowering the threshold for urgent referral and enabling easier direct access to investigations by PCPs, may provide the greatest benefit, as other recent studies indicate (Maclean et al, 2015; Moller et al, 2015).

The study displays the immense complexity and difficulty of diagnosing cancer. Further research on similar combined data sets from longitudinal studies, using the same novel analytical approach, should now be conducted to confirm the relative impact of primary and secondary care diagnostic intervals on outcomes in patients with other cancers.

\section{CONCLUSION}

This study provides evidence that longer primary care and secondary care intervals are associated with more advanced CRC. The finding of similar trends when using different sources of information, for different time periods and in different health-care systems (of Scotland, England, Canada, Denmark and Spain) strengthens the belief that the results can be generalised to other health-care systems around the world.

\section{ACKNOWLEDGEMENTS}

The authors are all members of the Cancer in Primary Care Research International (CaPRI) Network. We are thankful to the CRUX, CAPER, ALBERTA, CRCDK, DECCIRE, CAP and NACDPC research teams for contributing data as well as detailed knowledge about the way it was collected. We are equally thankful to the participating general practices, hospitals, service agencies, and patients for their time and involvement. In addition, we would like to express our gratitude to associate professor Morten Frydenberg from the Department of Biostatistics at Aarhus University for statistical support and making programmes available for generating cubic splines with specific reference values (centercsplines.ado) and estimates with standard errors for linear combinations (calcest.ado) in Stata (applied in Figures 3-5 and in Supplementary Figure 6). To bioinformatics Martin Krzywinski at the Genome Science Centre in Vancouver for his advice on improving the data visualisation of Figure 3. To Jochim Terhaar sive Droste from the Department of Gastroenterology and Hepatology, VU University Medical Centre, Amsterdam for his initial collaboration and willingness to share data from the Northern Holland cohort. The workgroup sincerely thanks Dr Fiona Walter and the Early Diagnosis Group at Cambridge's Primary Care Unit for providing a perfect space for thinking, working and writing together in the autumn of 2014.

\section{CONFLICT OF INTEREST}

The authors declare no conflict of interest.

\section{AUTHOR CONTRIBUTIONS}

GR and MLT initiated the CaPRI Colorectal Cancer Collaboration Workgroup and came up with the idea for the study. MLT, PM and GR evolved the study design in subsequent meetings and discussions. All authors collaborated on drafting an analysis plan and prepared their individual data sets in accordance with the agreed protocol. The author and data custodian of the CRCDK data, M Lautrup is identical with $M$ Korsgaard as cited in the reference list. MLT co-ordinated communication with and data acquisition from involved research groups, performed the statistical analyses, and wrote the paper together with PM. She (MLT) is the guarantor. GR, PV and WH provided critical revision of the intellectual content of the manuscript. All authors had full access to their own data set and take full responsibility for the accuracy of the data description and analysis. All authors contributed to the writing of and approved the final manuscript.

\section{DISCLAIMER}

The guarantor, MLT, affirms that this manuscript is an honest, accurate, and transparent account of the study being reported; that no important aspects of the study have been omitted; and that all discrepancies from the study as planned have been explained.

\section{ETHICAL APPROVAL}

MLT was granted permission to analyse data according to the laws in each country. The CRUX study was approved by the Privacy Advisory Committee of ISD Scotland. According to the North of Scotland Research Ethics Committee formal ethical approval was not required. Research and Development approval was granted from NHS Grampian. In the CAPER study ethical approval was obtained from North and East Devon local research ethics committee. All patients in the CRCDK study signed an informed consent form and the study was approved by the Danish Data Protection Agency and the Ethical Committees of Aarhus, Ringkoebing and Ribe counties. The principle investigator of the ALBERTA data set obtained necessary regulatory approvals to send data to MLT. The CAP study was approved by the Danish Data Protection Agency. The Danish Health and Medicines Authority gave permission to obtain information from the PCPs' medical records. Health research ethics was not required. The DECCIRE study was approved by the Primary Health-Care Committee of each health district and by the Ethical and Clinical Research Committee of each participating region in Spain. The NACDPC audit was approved as an audit by the Research and Audit committees of the Primary Care Trusts of participating practices. Permission to use anonymised data for research purposes was granted by the NACDPC oversight group.

\section{FUNDING}

The CaPri Colorectal Cancer Collaboration project received no formally targeted donations, but, the primary author MLT coordinated the work as part of her postdoctoral studies at the Research Centre for Cancer Diagnosis in Primary Care (CaP), funded by the Novo Nordisk Foundation and the Danish Cancer Society. The CRUX study was funded by NHS Grampian Research Endowment Award 11/26, and a grant from The Colorectal Study Fund (a NHS Grampian Endowment fund). The CAPER study was funded by the Department of Health, UK. The CRCDK study was supported by grants from Western Danish Research Forum, Danish Medical Research Council, Dagmar Marshall's Fund and the Danish Cancer Society. The ALBERTA was funded by the National Cancer Institute of Canada, Alberta Cancer Foundation, and the Canadian Institute of Health Research. The CAP study was supported by the Novo Nordisk Foundation, the Danish Cancer Society, the Health Foundation, the Tryg Foundation, and the 
Central Denmark Region's 'Praksisforskningsfond'. The DECCIRE study was financed with grants from the Ministry of Health, Carlos III Institute, and also received support from the Health Promotion and Preventive Activities-Primary Health-Care Network, sustained by the Ministry of Health in Spain. The NACDPC study was financed by the Department of Health, England. The sponsors were not involved in any part of the studies.

\section{REFERENCES}

Adelstein BA, Irwig L, Macaskill P, Katelaris PH, Jones DB, Bokey L (2008) A self administered reliable questionnaire to assess lower bowel symptoms. BMC Gastroenterol 8: 8.

Afzelius P, Zedeler K, Sommer H, Mouridsen HT, Blichert-Toft M (1994) Patient's and doctor's delay in primary breast cancer: prognostic implications. Acta Oncol 33: 345-351.

Banks J, Walter FM, Hall N, Mills K, Hamilton W, Turner KM (2014) Decision making and referral from primary care for possible lung and colorectal cancer: a qualitative study of patients' experiences. $\mathrm{Br} J \mathrm{Gen}$ Pract 64: e775-e782.

Benitez-Majano S, Fowler H, Maringe C, Di Girolamo C, Rachet B (2016) Deriving stage at diagnosis from multiple population-based sources: colorectal and lung cancer in England. Br J Cancer 115: 391-400.

Crawford SC, Davis JA, Siddiqui NA, de Caestecker L, Gillis CR, Hole D, Penney G (2002) The waiting time paradox: population based retrospective study of treatment delay and survival of women with endometrial cancer in Scotland. BMJ 325: 196.

Durrleman S, Simon R (1989) Flexible regression models with cubic splines. Stat Med 8: 551-561.

Esteva M, Leiva A, Ramos M, Pita-Fernandez S, Gonzalez-Lujan L, Casamitjana M, Sanchez MA, Pertega-Diaz S, Ruiz A,

Gonzalez-Santamaria P, Martin-Rabadan M, Costa-Alcaraz AM, Espi A, Macia F, Segura JM, Lafita S, Arnal-Monreal F, Amengual I,

Bosca-Watts MM, Hospital A, Manzano H, Magallon R, DECCIRE Group (2013) Factors related with symptom duration until diagnosis and treatment of symptomatic colorectal cancer. BMC Cancer 13: 87.

Esteva M, Ramos M, Cabeza E, Llobera J, Ruiz A, Pita S, Segura JM, Cortes JM, Gonzalez-Lujan L, DECCIRE Research Group (2007) Factors influencing delay in the diagnosis of colorectal cancer: a study protocol. BMC Cancer 7: 86.

Hamilton W (2010) Cancer diagnosis in primary care. Br J Gen Pract 60: 121-128.

Hamilton W, Round A, Sharp D, Peters TJ (2005) Clinical features of colorectal cancer before diagnosis: a population-based case-control study. Br J Cancer 93: 399-405.

Hamilton W, Sharp D (2004) Diagnosis of colorectal cancer in primary care: the evidence base for guidelines. Fam Pract 21: 99-106.

Hansen RP, Vedsted P, Sokolowski I, Sondergaard J, Olesen F (2011) Time intervals from first symptom to treatment of cancer: a cohort study of 2,212 newly diagnosed cancer patients. BMC Health Serv Res 11: 284.

Iversen LH, Antonsen S, Laurberg S, Lautrup MD (2009) Therapeutic delay reduces survival of rectal cancer but not of colonic cancer. Br J Surg 96: $1183-1189$.

Jensen H, Torring ML, Olesen F, Overgaard J, Vedsted P (2014a) Cancer suspicion in general practice, urgent referral and time to diagnosis: a population-based GP survey and registry study. BMC Cancer 14: 636-2407-14-636.

Jensen H, Torring ML, Larsen M, Bach, Vedsted P (2014b) Existing data sources for clinical epidemiology: Danish Cancer in Primary Care cohort. Clin Epidemiol 6: 237-246.

Korsgaard M, Pedersen L, Sorensen HT, Laurberg S (2006a) Delay of treatment is associated with advanced stage of rectal cancer but not of colon cancer. Cancer Detect Prev 30: 341-346.

Korsgaard M, Pedersen L, Sorensen HT, Laurberg S (2006b) Reported symptoms, diagnostic delay and stage of colorectal cancer: a populationbased study in Denmark. Colorectal Dis 8: 688-695.

Lynch BM, Youlden D, Fritschi L, Newman B, Pakenham KI, Leggett B, Owen N, Aitken JF (2008) Self-reported information on the diagnosis of colorectal cancer was reliable but not necessarily valid. J Clin Epidemiol 61: 498-504.
Lyratzopoulos G, Abel GA, McPhail S, Neal RD, Rubin GP (2013) Gender inequalities in the promptness of diagnosis of bladder and renal cancer after symptomatic presentation: evidence from secondary analysis of an English primary care audit survey. BMJ Open 3: e002861.

Maclean R, Jeffreys M, Ives A, Jones T, Verne J, Ben-Shlomo Y (2015) Primary care characteristics and stage of cancer at diagnosis using data from the national cancer registration service, quality outcomes framework and general practice information. BMC Cancer 15: 500-015-1497-1.

Maguire A, Porta M, Malats N, Gallen M, Pinol JL, Fernandez E (1994) Cancer survival and the duration of symptoms. An analysis of possible forms of the risk function. ISDS II Project Investigators. Eur J Cancer 30: 785-792.

Moller H, Gildea C, Meechan D, Rubin G, Round T, Vedsted P (2015) Use of the English urgent referral pathway for suspected cancer and mortality in patients with cancer: cohort study. BMJ 351: h5102.

Murchie P, Raja EA, Brewster DH, Campbell NC, Ritchie LD, Robertson R, Samuel L, Gray N, Lee AJ (2014) Time from first presentation in primary care to treatment of symptomatic colorectal cancer: effect on disease stage and survival. Br J Cancer 111: 461-469.

Neal RD, Din NU, Hamilton W, Ukoumunne OC, Carter B, Stapley S, Rubin G (2014) Comparison of cancer diagnostic intervals before and after implementation of NICE guidelines: analysis of data from the UK General Practice Research Database. Br J Cancer 110: 584-592.

Neal RD, Tharmanathan P, France B, Din NU, Cotton S, Fallon-Ferguson J, Hamilton W, Hendry A, Hendry M, Lewis R, Macleod U, Mitchell ED, Pickett M, Rai T, Shaw K, Stuart N, Torring ML, Wilkinson C, Williams B, Williams N, Emery J (2015) Is increased time to diagnosis and treatment in symptomatic cancer associated with poorer outcomes? Systematic review. Br J Cancer 112(Suppl): S92-S107.

NICE (2005) Referral guidelines for suspected cancer. Br J Gen Pract 55(517): $580-581$.

Ostenfeld EB, Froslev T, Friis S, Gandrup P, Madsen MR, Sogaard M (2012) Completeness of colon and rectal cancer staging in the Danish Cancer Registry, 2004-2009. Clin Epidemiol 4(Suppl 2): 33-38.

Probst HB, Hussain ZB, Andersen O (2012) Cancer patient pathways in Denmark as a joint effort between bureaucrats, health professionals and politicians-a National Danish Project. Health Policy 105: 65-70.

Ramos M, Esteva M, Cabeza E, Campillo C, Llobera J, Aguilo A (2007) Relationship of diagnostic and therapeutic delay with survival in colorectal cancer: a review. Eur J Cancer 43: 2467-2478.

Ramos M, Esteva M, Cabeza E, Llobera J, Ruiz A (2008) Lack of association between diagnostic and therapeutic delay and stage of colorectal cancer. Eur J Cancer 44: 510-521.

Richards MA (2009) The National awareness and early diagnosis initiative in England: assembling the evidence. Br J Cancer 101(Suppl 2): S1-S4.

Robertson R, Campbell NC, Smith S, Donnan PT, Sullivan F, Duffy R, Ritchie LD, Millar D, Cassidy J, Munro A (2004) Factors influencing time from presentation to treatment of colorectal and breast cancer in urban and rural areas. Br J Cancer 90: 1479-1485.

Rubin G, McPhail S, Elliott K (2011) National Audit of Cancer Diagnosis in Primary Care. Royal College of General Practitioners: London, UK.

Rupassara KS, Ponnusamy S, Withanage N, Milewski PJ (2006) A paradox explained? Patients with delayed diagnosis of symptomatic colorectal cancer have good prognosis. Colorectal Dis 8: 423-429.

Scottish Intercollegiate Guidelines Network (SIGN) (2011) Diagnosis and management of colorectal cancer. Edinburgh: SIGN publication no. 126. Available from URL: http://www.sign.ac.uk.

Stapley S, Peters TJ, Sharp D, Hamilton W (2006) The mortality of colorectal cancer in relation to the initial symptom at presentation to primary care and to the duration of symptoms: a cohort study using medical records. $\mathrm{Br}$ J Cancer 95: 1321-1325.

Symonds RP (2002) Cancer biology may be more important than diagnostic delay. Comment on : Crawford SC, Davis JA, Siddiqui NA et al The waiting time paradox: population based retrospective study of treatment delay and survival of women with endometrial cancer in Scotland. BMJ 2002;325:196 (27 July). BMJ 325: 774-774.

Tate AR, Martin AG, Murray-Thomas T, Anderson SR, Cassell JA (2009) Determining the date of diagnosis-is it a simple matter? The impact of different approaches to dating diagnosis on estimates of delayed care for ovarian cancer in UK primary care. BMC Med Res Methodol 9: $422288-9-42$. 
Tørring ML, Frydenberg M, Hansen RP, Olesen F, Hamilton W, Vedsted P (2011) Time to diagnosis and mortality in colorectal cancer: a cohort study in primary care. Br J Cancer 104: 934-940.

Tørring ML, Frydenberg M, Hansen RP, Olesen F, Vedsted P (2012) Diagnostic interval and mortality in colorectal cancer: U-shaped association demonstrated for three different datasets. J Clin Epidemiol 65: 669-678.

Tucker TC, Howe HL, Weir HK (1999) Certification for population-based cancer registries. J Registry Manag 26: 24-27.

Walters S, Maringe C, Butler J, Brierley JD, Rachet B, Coleman MP (2013) Comparability of stage data in cancer registries in six countries: lessons from the International Cancer Benchmarking Partnership. Int J Cancer 132: $676-685$.
Weller D, Vedsted P, Rubin G, Walter FM, Emery J, Scott S, Campbell C, Andersen RS, Hamilton W, Olesen F, Rose P, Nafees S, van Rijswijk E, Hiom S, Muth C, Beyer M, Neal RD (2012) The Aarhus statement: improving design and reporting of studies on early cancer diagnosis. $\mathrm{Br} \mathrm{J}$ Cancer 106: 1262-1267.

This work is published under the standard license to publish agreement. After 12 months the work will become freely available and the license terms will switch to a Creative Commons AttributionNonCommercial-Share Alike 4.0 Unported License.

Supplementary Information accompanies this paper on British Journal of Cancer website (http://www.nature.com/bjc) 